\title{
Retinal detachment following excimer laser
}

\author{
D G Charteris, R J Cooling, M J Lavin, D McLeod
}

\begin{abstract}
Aims-To report the clinical presentation, surgical management, and outcome of retinal detachment following excimer laser.

Methods-Retrospective analysis of retinal detachments observed in 11 eyes of 10 myopic patients who had previously undergone photorefractive keratectomy (PRK) or phototherapeutic keratectomy (PTK) by excimer laser.

Results-Symptoms of visual loss in two eyes were initially attributed to corneal haze. In 10 of 11 eyes visualisation of the retinal detachment and causative break was possible despite mild corneal haze and optical aberrations caused by the refractive laser procedure. Retinal reattachment was achieved in all 11 eyes though one eye required four surgical interventions.

Conclusion-This is the first published report to describe an association between retinal detachment and previous excimer laser treatment. The association would appear to reflect the predisposition of myopes to retinal detachment. Clinicians should be aware of potential retinal pathology in patients undergoing PRK. (Br F Ophthalmol 1997;81:759-761)
\end{abstract}

The increasing numbers of patients undergoing photorefractive keratectomy (PRK) by excimer laser has led to an awareness of the potential hazards and complications of this procedure. In general, these are related to the local effects on the ocular anterior segment. However, several patients who had previously undergone PRK or phototherapeutic keratectomy (PTK) recently presented with rhegmatogenous retinal detachment. This report documents these cases and considers the possible association of retinal detachment with PRK and PTK.

Moorfields Eye Hospital, City Road, London EC1V 2PD

D G Charteris

R J Cooling

Manchester Royal Eye Hospital, Oxford Road, Manchester M13 9WH D G Charteris

M J Lavin

D McLeod

Correspondence to: Mr D G Charteris,

Moorfields Eye Hospital,

City Road, London EC1V 2PD.

Accepted for publication 27 May 1997 Eye Hospital or Manchester Royal Eye Hospie presenting features, outcomes, issues surrounding the evaluation and treatagement, and outcome of these patients is summarised in Table 1 . None of the patients

Results was taking any ophthalmic medication before laser treatment. Nine of the 10 patients had undergone PRK to correct myopia. Five of these patients (cases 2, 3, 5, 7, and 8) had had bilateral PRK. The tenth patient (case 6, Table 1), who was also moderately myopic, had unilateral PTK for band keratopathy and vascularised corneal scarring of uncertain aetiology. One patient (case 1) had sustained right sided facial and ocular trauma 9 months after PRK and 2 months before presentation and one patient (case 8) had sustained direct ocular trauma 7 months after PRK and 1 month before presentation.

Patients who had undergone PRK (that is, cases 1-5, 7-10, Table1) presented with symptoms of photopsia and/or visual field loss except for the asymptomatic peripheral retinal detachment in the right eye of case 3 . One patient (case 7) developed acute onset of a floater 6 months after PRK and 4 months before retinal detachment; retinal examination at the time of onset of the floater was normal. Diagnosis of retinal detachment involving the macula was delayed in two patients, in one (case 2) because loss of visual acuity which was initially attributed to post-laser corneal haze and in the other (case 6) for 3 months, because of the difficulty in viewing the retina through a scarred and opacified cornea.

In three patients (cases 2, $3(\mathrm{~L})$, and 5) the clinical picture at presentation suggested extension of longstanding retinal detachments and it is possible that these detachments may have been present but undiagnosed at the time of PRK.

One patient (case 4) presented with retinal breaks associated with lattice degeneration and developed further tractional retinal tears following initially successful retinal surgery. Four of the 10 patients had lattice degeneration in both detached and fellow eyes. None of the four fellow eyes which had not undergone PRK (cases 1, 4, 9, and 10) developed retinal detachment within the time frame of the series (nor had any patient presented with unilateral retinal detachment where the contralateral eye had undergone PRK).

Although it caused distortion of the retinal image the central keratectomy did not preclude viewing of the peripheral retina or retinal breaks after PRK (cases 1-5, 7-10). There was spontaneous loss of the central corneal epithelium during surgery in case 1 and a central corneal epithelial defect was noted in case 4 postoperatively. In case 6 the pre-existing corneal scarring and central keratectomy combined to significantly impair the fundal view both pre- and peroperatively. 
Table 1 Presenting features and surgical outcome in 11 eyes of 10 patients with retinal detachment following excimer laser keratoplasty

\begin{tabular}{|c|c|c|c|c|c|c|c|c|}
\hline $\begin{array}{l}\text { Patient/ } \\
\text { age/sex }\end{array}$ & Eye & $\begin{array}{l}\text { Pre-PRK } \\
\text { refraction } \\
\left({ }^{\star} \text { PTK) }\right.\end{array}$ & $\begin{array}{l}\text { Interval PRK/PTK to } \\
R D \text { diagnosis (months) }\end{array}$ & Preop VA & $\begin{array}{l}\text { Breaks } \\
\text { Macula } \\
\text { Longevity }\end{array}$ & Surgery & Outcome/retinal status & $V A$ \\
\hline $1 / 26 / \mathrm{M}$ & $\mathrm{R}$ & $-8.00 \mathrm{R} \& \mathrm{~L}$ & 11 & $6 / 12$ & $\begin{array}{l}\times 2 \text { oral dialyses } \\
\text { Macula attached }\end{array}$ & $\mathrm{D}, \mathrm{G}, \mathrm{C}, \mathrm{E}$ & Attached & $6 / 9$ \\
\hline $2 / 55 / \mathrm{M}$ & $\mathrm{L}$ & Myope & 1 & $6 / 36$ & $\begin{array}{l}\times 2 \text { atrophic breaks } \\
\text { Macula detached } \\
\text { Demarcation line and } \\
\text { subretinal fibrosis }\end{array}$ & $\mathrm{D}, \mathrm{C}, \mathrm{B}$ & Attached & $6 / 18$ \\
\hline $3 / 37 / M$ & $\mathrm{~L}$ & -3.50 & 3 & $6 / 9$ & $\begin{array}{l}\times 4 \text { ' } U \text { ' tears } \\
\text { Lattice } \\
\text { Macula attached }\end{array}$ & $\mathrm{V}, \mathrm{C}, \mathrm{G}, \mathrm{B}$ & Attached & $6 / 9$ \\
\hline & $\mathrm{R}$ & -3.00 & 3 & $6 / 6$ & $\begin{array}{l}\text { Atrophic holes } \\
\text { Lattice } \\
\text { Macula attached }\end{array}$ & $\mathrm{C}, \mathrm{B}$ & Attached & $6 / 12$ \\
\hline $4 / 27 / M$ & $\mathrm{R}$ & -15.50 & 3 & $6 / 5$ & $\begin{array}{l}\text { Atrophic holes } \\
\text { Lattice } \\
\text { Macula attached }\end{array}$ & $\begin{array}{l}4 \text { procedures } \\
\text { (1) V, EL, G } \\
\text { (2) } \mathrm{L}, \mathrm{G} \\
\text { (3) O } \\
\text { (4) RO }\end{array}$ & $\begin{array}{l}\text { Attached } \\
\text { (Chronic ocular } \\
\text { surface irritation) }\end{array}$ & $6 / 18$ \\
\hline $5 / 48 / \mathrm{M}$ & $\mathrm{L}$ & myope & 20 & $\mathrm{CF}$ & $\begin{array}{l}\text { Retinal dialysis } \\
\text { Atrophic breaks } \\
\text { Lattice inferiorly } \\
\text { Macula detached }\end{array}$ & $\mathrm{D}, \mathrm{C}, \mathrm{E}, \mathrm{B}$ & Attached & $6 / 12$ \\
\hline $6 / 56 / F$ & $\mathrm{R}$ & $-5.50^{\star}$ & $7^{\star}$ & $2 / 60$ & $\begin{array}{l}\text { Macular hole } \\
\text { Macula detached } \\
\text { PVR }\end{array}$ & V, R, O & $\begin{array}{l}\text { Attached } \\
\text { (oil in situ) } \\
\text { Cataract }\end{array}$ & $6 / 60$ \\
\hline $7 / 49 / \mathrm{M}$ & $\mathrm{L}$ & $-6.50 \mathrm{R} \& \mathrm{~L}$ & $\begin{array}{l}10 \text { (floater } 4 \text { months } \\
\text { before) }\end{array}$ & $6 / 6$ & $\begin{array}{l}\times 1 \text { 'U' tear } \\
\text { Macula attached }\end{array}$ & $\mathrm{D}, \mathrm{C}, \mathrm{B}$ & Attached & $6 / 6$ \\
\hline $8 / 34 / \mathrm{M}$ & $\mathrm{L}$ & $-19.00 \mathrm{R} \& \mathrm{~L}$ & $\begin{array}{l}8 \text { (trauma } 1 \text { month } \\
\text { before RD) }\end{array}$ & $6 / 36$ & $\begin{array}{l}\text { Giant retinal tear and } \times 3 \text { ' } U \text { ' } \\
\text { tears } \\
\text { Macula attached }\end{array}$ & V, E, G, EL & Attached & $6 / 36$ \\
\hline $9 / 24 / \mathrm{F}$ & $\mathrm{R}$ & -14.00 & 1 & PL & $\begin{array}{l}\times 4 \text { 'U' tears } \\
\text { Vitreous haemorrhage } \\
\text { PVR } \\
\text { Macula detached }\end{array}$ & $\begin{array}{l}2 \text { procedures } \\
\text { (1) C, E, G (2) } \\
\text { V, R, O, EL }\end{array}$ & $\begin{array}{l}\text { Attached } \\
\text { Silicone oil in situ }\end{array}$ & $\mathrm{HM}$ \\
\hline $10 / 32 / \mathrm{M}$ & $\mathrm{L}$ & -26.00 & 6 & HM & $\begin{array}{l}\text { Giant retinal tear and } \times 1 \text { ' } U \text { ' } \\
\text { tear } \\
\text { Lattice } \\
\text { Macula detached }\end{array}$ & $\begin{array}{l}2 \text { procedures } \\
\text { (1) V, O, El, B } \\
\text { (2) RO }\end{array}$ & Attached & $6 / 60$ \\
\hline
\end{tabular}

$\mathrm{RD}=$ retinal detachment $\mathrm{PVR}=$ proliferative vitreoretinopathy; VA = corrected visual acuity; $\mathrm{D}=$ drainage of subretinal fluid; $\mathrm{G}=$ gas $\left.\mathrm{SF} / \mathrm{C}_{3} \mathrm{~F}_{8}\right) ; \mathrm{C}=$ cryo; $\mathrm{E}=$ encirclement; $\mathrm{B}=$ buckle; $\mathrm{V}=$ vitrectomy; $\mathrm{EL}=$ endolaser; $\mathrm{O}=$ silicone oil $\mathrm{RO}=$ removal of oil; $\mathrm{R}=$ retinectomy; $\mathrm{L}=$ lensectomy; $\mathrm{CF}=$ counting fingers; $\mathrm{HM}=$ hand movements; PL = perception of light.

In all 11 eyes retinal reattachment of at least 6 months' duration was achieved either by conventional scleral buckling or vitrectomy. In one patient (case 4) a total of four surgical procedures were performed and in two others (cases 6 and 9) silicone oil remains in situ.

\section{Discussion}

The results of excimer laser PRK for myopia have been documented in recent publications. ${ }^{12}$ The complications reported in these series were directly related to the procedure itself (for example, anterior corneal stromal haze, loss of acuity, epithelial instability) or to the postoperative management (for example, increased intraocular pressure due to topical steroids). This is the first report to describe retinal detachment in eyes which had previously undergone excimer laser PRK.

This series of retinal detachments form a heterogeneous group and appear to reflect the predisposition of myopes to rhegmatogenous retinal detachment (albeit there was a clear history of post-PRK trauma in two eyes (cases 1 and 8 ). Myopes comprise $34-79 \%$ of patients in various series of retinal detachments ${ }^{34}$ and the predisposition is considered to be due to premature vitreous liquefaction and/or posterior vitreous detachment together with an increased prevalence of lattice degeneration. ${ }^{5}$ Lattice degeneration was evident in four of the 10 patients in our series. Hyams and Neumann described asymptomatic retinal breaks in $11 \%$ of 332 asymptomatic myopic eyes. ${ }^{6}$ Hence, myopic patients undergoing excimer laser PRK are likely to be at greater risk of retinal detachment than the general population.

The retinal detachments reported following other refractive surgical procedures such as radial keratotomy and keratomileusis occurred between 3 and 7 years after the surgery ${ }^{7}$; retinal detachment was considered to be a consequence of myopia and was not attributed to the refractive surgery. The retinal detachments in the six patients in our series presented at 1-20 months following excimer laser PRK or PTK but it still appears unlikely that the detachments were a direct result of the refractive laser procedure. Nevertheless, it is possible that the acoustic shock waves generated within the globe at the time of excimer laser keratectomy ${ }^{8}$ might precipitate a detachment or extension of detachment in an eye with predisposing vitreoretinal pathology, although the pathophysiological basis for this remains uncertain.

It is notable that this series contains a significant proportion of high myopes (cases 4 , 8-10), a group particularly predisposed to retinal detachment. PRK treatment in high myopia is, in general, less efficient and predictable than in the correction of low myopia ${ }^{19}$ and requires greater total laser energy. Two of the highly myopic patients in this series presented with giant retinal tears (although one of these appears to have been due to unrelated direct ocular trauma) and a cautious approach to 
PRK would seem appropriate in high myopes. Moreover, with the increased use of laser assisted intrastromal keratomileusis $(\mathrm{LASIK})^{1011}$ the numbers of high myopes undergoing laser corneal surgery are likely to increase.

Corneal stromal haze and the optical aberrations arising from the central laser keratectomy affected the retinal image in these patients. Nevertheless, the retinal view was still adequate to visualise the retinal breaks and perform retinal detachment surgery. In case 6 , where there was previous corneal scarring, the fundal view was considerably impaired despite PTK. Likewise the spontaneous loss of corneal epithelium which occurred peroperatively in case 1 also impaired the retinal image.

Given the association of excimer laser PRK and retinal detachment we recommend that patients undergoing PRK have a detailed fundal examination to detect any predisposing vitreoretinal pathology. Since (a) there is at present no causal link between excimer laser keratoplasty and subsequent retinal detachment and (b) the incidence of retinal detachment in eyes with asymptomatic lattice degeneration is relatively $\operatorname{low}^{12}$ we do not advocate prophylactic treatment of the retina in such eyes before PRK. However, in three of our patients, we found evidence of extension of longstanding retinal detachments and we recommend that subclinical retinal detach- ments (and tractional retinal tears) are treated before undertaking excimer laser. Similarly, in two of our patients their complaint of visual loss was not initially attributed to retinal detachment. It is therefore imperative that posterior segment complications are excluded before loss of acuity following PRK is attributed to corneal haze or other anterior segment complications.

1 Garty DS, Kerr Muir MG, Marshall J. Excimer laser photorefractive keratectomy. Ophthalmology 1992;99:120919.

2 Salz JJ, Maguen E, Nesburn AB, Warren C, Macy JI, Hofbauer JD, et al. A two-year experience with excimer laser photorefractive keratectomy for myopia. Ophthalmology 1993;100:873-82.

3 Schepens CL, Marden D. Data on the natural history of retinal detachment. Further characterisation of certain unilateral nontraumatic cases. Am $\mathcal{F}$ Ophthalmol 1966;61: 213-26.

4 Perkins ES. Morbidity from myopia. Sight Sav Rev 1979;49: Perkins

5 Michels RG, Wilkinson CP, Rice TA. Retinal detachment. St Louis: C V Mosby, 1990:76-84.

6 Hyams SW, Neumann E. Peripheral retina in myopia. Brf Ophthalmol 1969;53:300-6.

7 Rodriguez A, Camacho H. Retinal detachment after refractive surgery for myopia. Retina 1992;12:S46-S50.

8 Seiler T, McDonnell PJ. Excimer laser photorefractive keratectomy. Surv Ophthalmol 1995;40:89-118.

9 Heitzmann J, Binder PS, Kassar BS, Nordan LT. The correction of high myopia using the excimer laser. Arch Ophthalmol 1993;111:1627-34.

10 Gris O, Guell JL, Muller A. Keratomileusis update. 7 Cataract Refract Surg 1996;22:620-3

11 Condon PI, Mulhern M, Fulcher T, Foley-Nolan A, O'Keefe M. Laser intrastromal keratomileusis for high O'Keefe M. Laser intrastromal keratomileusis for high
myopia and myopic astigmatism. Br f Ophthalmol 1997;81: myopia and

12 Byer NE. Long-term natural history of lattice degeneration of the retina. Ophthalmology 1989;96:1396-402. 